\title{
Fluidization Characteristics of Medium-High-Consistency Pulp Fiber Suspensions with an Impeller
}

\author{
Ye Daoxing ${ }^{1}$ and Li Hong ${ }^{2}$ \\ ${ }^{1}$ Key Laboratory of Fluid and Power Machinery, Ministry of Education, School of Energy and Power Engineering, \\ Xihua University, Chengdu 610039, China \\ ${ }^{2}$ National Research Center of Pumps, Jiangsu University, Zhenjiang 212013, China \\ Correspondence should be addressed to Ye Daoxing; dxingye@163.com
}

Received 31 December 2015; Revised 18 April 2016; Accepted 20 April 2016

Academic Editor: Ryoichi Samuel Amano

Copyright (c) 2016 Y. Daoxing and L. Hong. This is an open access article distributed under the Creative Commons Attribution License, which permits unrestricted use, distribution, and reproduction in any medium, provided the original work is properly cited.

\begin{abstract}
When the mass concentration exceeds 7\%, pulp suspensions stop flowing and act like a solid. To investigate the fluidization characteristics of medium-high-consistency pulp suspensions and achieve pulp fluidization and pumping, experiments were carried out with waste tissue pulp and unbleached kraft pulp. The objectives of this paper were to study the rheology of mediumhigh-consistency pulp and to determine accurate parameters for the physical Herschel-Bulkley model. To validate this model, computational fluid dynamics (CFD) results were compared to experimental data. The simulation values were very similar and were in agreement with experimental results.
\end{abstract}

\section{Introduction}

Compared with low-consistency technology, medium-highconsistency technology, which uses pulp suspension mass concentrations from $5 \%$ to $40 \%$, is an efficient, low-energy, reduced-pollution process. The fluidization of pulp suspensions is an essential consideration in pulp and paper manufacturing. One of the most important pieces of equipment in medium-high-consistency pumping is the fluidization generator, which is indispensable for generating fluidization in pulp suspensions in the pump process.

Rheologically, pulp fiber suspensions behave like yieldpseudoplastic fluids [1]. To attain fluidization, the apparent yield stress must be exceeded. When the imposed shear stress is beyond the threshold value, pulp suspensions start flowing; like a solid body, networks develop at low shear rates and break down at high shear rates.

Bennington [2,3] and Hietaniemi and Gullichsen [4] found that fluidization could occur at a floc and fiber level because of large differences in the apparent yield stress. The latter studies measured the onset of fluidization, finding that this onset is common for turbulent flow in mixing vessels.
Hemstrom [5, 6] established the relationship between the flow velocity and the consistency of pulp suspensions in a completely turbulent state. In order to produce complete fluidization in a $10 \%$ concentration pulp fiber suspension, the pulp flow velocity must reach $45-50 \mathrm{~m} / \mathrm{s}$; this velocity was clearly very difficult to achieve, and the flow loss was very large. Duffy and Titchener [7] found the relationship between the critical shear stress and the consistency of pulp suspensions in a completely turbulent state, and several corresponding coefficients were given. Based on a previous study [7], additional experimental measurements were performed by Bennington et al. [2], and similar results were found. Experiments were carried out with seven kinds of mediumconsistency pulp fiber suspensions by K.-F. Chen and S.$M$. Chen [8], and formulas describing the critical shear stress were obtained. The commencement regime, transition regime, and turbulent regime were analyzed. Research showed that the shear stress of the fluidization generator for medium-consistency pulp depended on the rotational speed at a given shear stress.

Bhole et al. [9] measured the power number and the axial force number of low-consistency pulp fiber suspensions. 
TABLE 1: Geometrical parameters of experimental setup.

\begin{tabular}{lc}
\hline Geometrical parameters & Dimensions $(\mathrm{mm})$ \\
\hline Impeller diameter $(d)$ & 150 \\
Impeller height $(h)$ & 160 \\
Inside diameter of vessel $(D)$ & 440 \\
Outside diameter of vessel $\left(D_{1}\right)$ & 460 \\
Vessel height $(H)$ & 310 \\
Clearance from wall to bottom $(c)$ & 40 \\
\hline
\end{tabular}

CFD was used to model impeller flow using the Bingham approximation to describe the suspension rheology; model agreement with the experimental measurements was generally good, but there was still some error. Prajapati and Ein-Mozaffari [10] used Herschel-Bulkley model to simulate yield-pseudoplastic fluids and found good agreement. $\mathrm{Wu}$ [11] simulated non-Newtonian fluids using the HerschelBulkley model and found that realizable $\kappa-\varepsilon$ and standard $\kappa$ $\omega$ turbulence models reflected the fluids' rheological properties. Derakhshandeh [12] studied low-consistency pulp fiber suspensions using ultrasonic Doppler velocimetry, and the Herschel-Bulkley parameters and critical shear stress under turbulent conditions were obtained, and some other non-Newtonian fluids, such as sewage sludge, soft glassy materials, Kaolin suspensions, and bagasse pulp, were studied by Tabuteau et al. [13], Baudez et al. [14], Cotas et al. [15], Masalova et al. [16], and Li et al. [17].

The above studies mainly investigated the fluidization of low and partial medium-consistency pulp fiber suspensions, and CFD simulations were also focused on low-mediumconsistency pulp. A lack of medium-high-consistency pulp and corresponding simulations is apparent. Thus, the objective of this study was to measure the rheology of mediumhigh-consistency pulp and to determine accurate parameters for the physical model of medium-high-consistency pulp. To validate the model, CFD results were compared to experimental data.

\section{Experimental Setup and Theory}

In order to test the rheology characteristics, the experimental setup was designed as shown in the schematic diagram in Figure 1. The agitation impeller was driven by a $15 \mathrm{~kW}$ ABB inverter motor. The motor speed was controlled by an inverter to realize different speeds. The rotational speed, torque, and power signals were collected by a computer.

The details of the vessel and impeller dimensions are listed in Table 1.

Because the impeller-derived moment is zero in the pulp suspension, we obtain equation $M=\pi R^{2} h$. The shear stress is calculated by equation $\tau=M / \pi R^{2} h$. Metzner and Otto [18] found that when a non-Newtonian fluid is subjected to mechanical agitation, the average shear rate can be expressed as

$$
\dot{\gamma}=K_{s} N
$$

where $K_{s}$ is a constant value determined experimentally and $N$ is the impeller's rotational speed. Ayazi Shamlou and Edwards [19] proposed a correlation to estimate $K_{s}$ that was verified by Shekhar and Jayanti [20]:

$$
K_{s}=\left|33-172\left(\frac{c_{w}}{D}\right)\right|
$$

where $c_{w}$ is the impeller clearance from the vessel wall and $D$ is the inside diameter of the vessel. It can be seen that $K_{s}$ is a function of the geometric parameters of the impeller and experimental vessel, not the fluid rheology.

\section{CFD Simulation}

In order to describe the rheology characteristics of a mediumhigh-consistency pulp fiber suspension and obtain mutual verification of experiments and simulations, the following assumptions were proposed:

(1) The model is single-phase, and agitation in the vessel is performed under laminar flow.

(2) The fluid temperature is constant at $25^{\circ} \mathrm{C}$, and the fluid is non-Newtonian and, therefore, isothermal and incompressible.

3.1. Governing Equations. The governing equations for mechanical agitation under laminar flow are generally expressed as

$$
\begin{gathered}
\frac{\partial \rho}{\partial t}+\nabla \cdot(\rho \vec{u})=0 \\
\frac{\partial}{\partial t}(\rho \vec{u})+\nabla \cdot(\rho \vec{u} \vec{u})=-\nabla p+\nabla \cdot \overline{\bar{\tau}}+\vec{F}
\end{gathered}
$$

where $\rho$ is liquid density, $t$ is time, $\vec{u}$ is pulp flow velocity, $p$ is static pressure, $\overline{\bar{\tau}}$ is viscous stress, and $\vec{F}$ is body force.

3.2. Mesh Generation. In the present work, the flow domain in the vessel was discretized with a high-quality structured hexahedral mesh using ANSYS-ICEM, and the impeller mesh was refined as shown in Figure 2. The mesh quality has a significant effect on the accuracy of numerical results. The minimum ratio of the hexahedral mesh quality was above 0.2 , and the mix-angle was larger than 40 degrees. In general, the grid had to be fine enough to calculate the flow details, especially in some complex regimes, but not so fine that excessive time was required to solve the flow field.

Grid independency was checked as shown in Table 2 by demonstrating that additional cells did not change the torque by more than $2 \%$ compared to the fine-cell model. Five different numbers of cells were tested for $6.62 \%$ waste tissue pulp at $500 \mathrm{rpm}$. Compared to the fine-cell model, the torque deviated by $1.4 \%$ for Grid D, with $1.7 \times 10^{6}$ cells in the mesh. 
TABLE 2: Grid independency.

\begin{tabular}{lccccc}
\hline Characteristics & Impeller grid cells & Vessel grid cells & Total cells & Torque (Nm) & Deviation (\%) \\
\hline Grid A & $2 \times 10^{5}$ & $3.7 \times 10^{5}$ & $5.7 \times 10^{5}$ & 55.84 & 44.7 \\
Grid B & $3.3 \times 10^{5}$ & $5.1 \times 10^{5}$ & $8.4 \times 10^{5}$ & 47.67 & 23.53 \\
Grid C & $4.5 \times 10^{5}$ & $7.6 \times 10^{5}$ & $1.2 \times 10^{6}$ & 40.52 & 5 \\
Grid D & $6.8 \times 10^{5}$ & $9.8 \times 10^{5}$ & $1.7 \times 10^{6}$ & 39.13 & 1.4 \\
Grid E & $8.7 \times 10^{5}$ & $1.3 \times 10^{6}$ & $2.2 \times 10^{6}$ & 38.59 & - \\
\hline
\end{tabular}
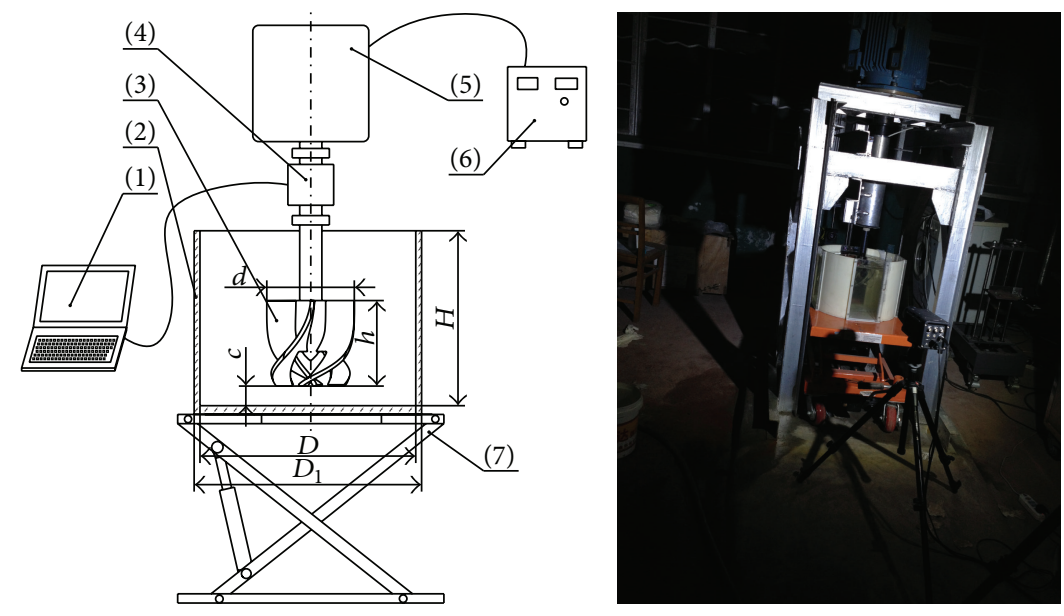
(1) Computer
(5) Inverter motor
(2) Agitation vessel
(6) Inverter
(3) Impeller
(7) Lifting platform
(4) Dynamometer

FIGURE 1: Schematic diagram of the experimental setup.

3.3. Rheology Model. The pulp fiber suspensions demonstrated yield-pseudoplastic behavior and acted as shear thinning fluids. Thus, the Herschel-Bulkley model [9, 21-23] was used to describe the pulp behavior under shear stress:

$$
\begin{gathered}
\eta=\mu_{0} \quad \text { for } \tau \leq \tau_{y}, \\
\eta=\frac{\tau_{y}+k\left[\dot{\gamma}^{n}-\left(\tau_{y} / \mu_{0}\right)^{n}\right]}{\dot{\gamma}} \quad \text { with } \tau>\tau_{y},
\end{gathered}
$$

where $\mu_{0}$ is yield viscosity, $\tau_{y}$ is yield stress, $k$ is thecoefficient index of consistency, $\dot{\gamma}$ is the average shear rate, and $n$ is the power law index.

3.4. CFD Methodology. All walls of the flow domain were modeled using a no-slip wall condition. The wall roughness was set to $0.03 \mathrm{~mm}$. Turbulence was simulated with a laminar model, and pulp flow was simulated under laminar flow conditions. In a turbulent state, the turbulence model was the RNG $k-\varepsilon$ model. A frozen-rotor interface was used for the coupling connection between the stationary and rotational frames, using quality and velocity transformations. A general grid interface (GGI) between the stationary and rotational components was used for internal component connections. A scalable wall-function was used to solve the boundary layer field. The average residual convergence criterion was set to $1 \times$ $10^{-5}$. As a simulation convergence judgment, impeller torque fluctuations within no more than 5\% every 100 steps were required. The commercial software CFX 14.0 was applied to solve the 3D Reynolds-averaged Navier-Stokes equations. The simulations in this work were carried out on a cluster of twenty Xeon E5-2670V2 nodes with $128 \mathrm{~GB}$ of RAM. The CFD calculations are steady-state.

\section{Results and Discussions}

4.1. Experimental Results. In this study, the shear rate and shear stress of different consistencies of waste tissue pulp and unbleached kraft pulp were obtained using the experimental setup shown in Figure 1. Figures 3 and 4 show the relationship between the shear stress and shear rate. The shear stress increased with shear rate and pulp consistency. When the shear stress was in the turbulent regime, the shear stress increased linearly. The calculated apparent yield stress, consistency index, and power law index values predicted by the Herschel-Bulkley model by using regression analysis are shown in Tables 3 and 4 . The apparent yield stress and consistency index increased with increasing consistency, but the power law index decreased. The Herschel-Bulkley model agrees well with the experimental flow data until the onset of the turbulent regime. 


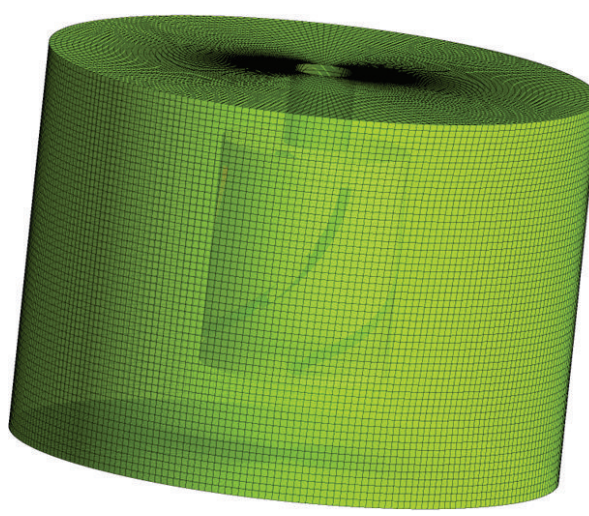

(a)

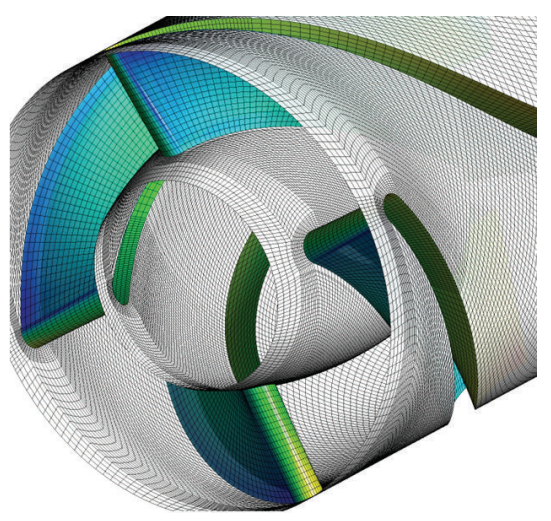

(b)

Figure 2: Mesh generation ((a): vessel and (b) details of impeller).

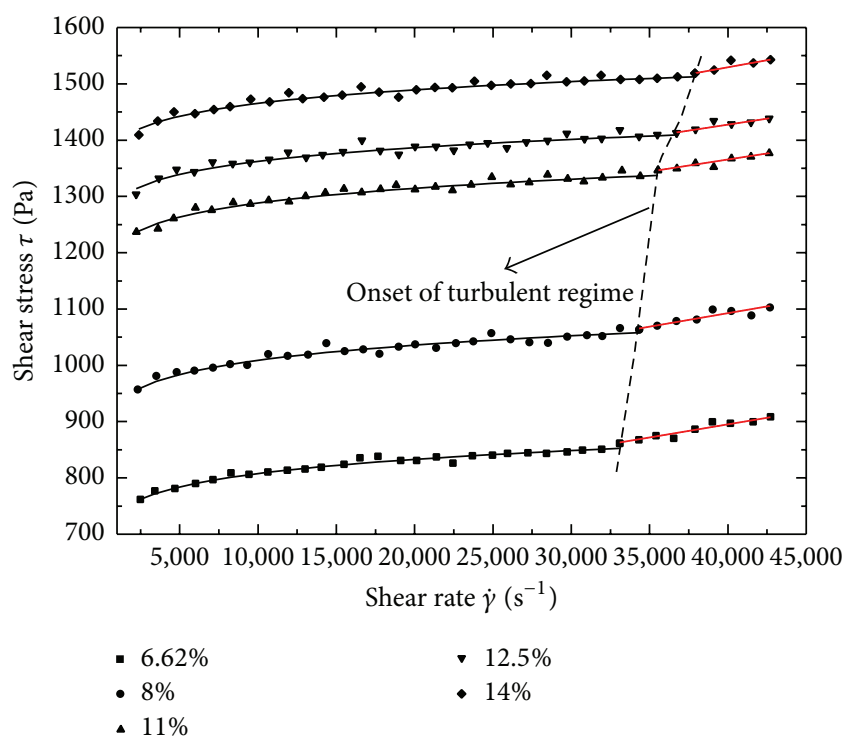

Figure 3: Shear stress versus shear rate of waste tissue pulp and several mass concentrations.

TABLE 3: Herschel-Bulkley constants for waste tissue pulp suspensions as a function of the fiber mass concentration.

\begin{tabular}{lccc}
\hline Mass concentration (\%) & $\tau_{y}$ & $k$ & $n$ \\
\hline 6.62 & 456 & 140 & 0.1 \\
8 & 613 & 165 & 0.095 \\
11 & 867 & 189 & 0.087 \\
12.5 & 936 & 204 & 0.08 \\
14 & 1003 & 236 & 0.073 \\
\hline
\end{tabular}

4.2. CFD Validation. Based on the Herschel-Bulkley model constants obtained from experimental data and shown in Tables 3 and 4, pulp suspension flows were simulated for several mass concentrations of pulp. The power number can be used as a basis of comparison; this value is given by

$$
N_{p}=\frac{P}{\rho N^{3} d^{5}},
$$

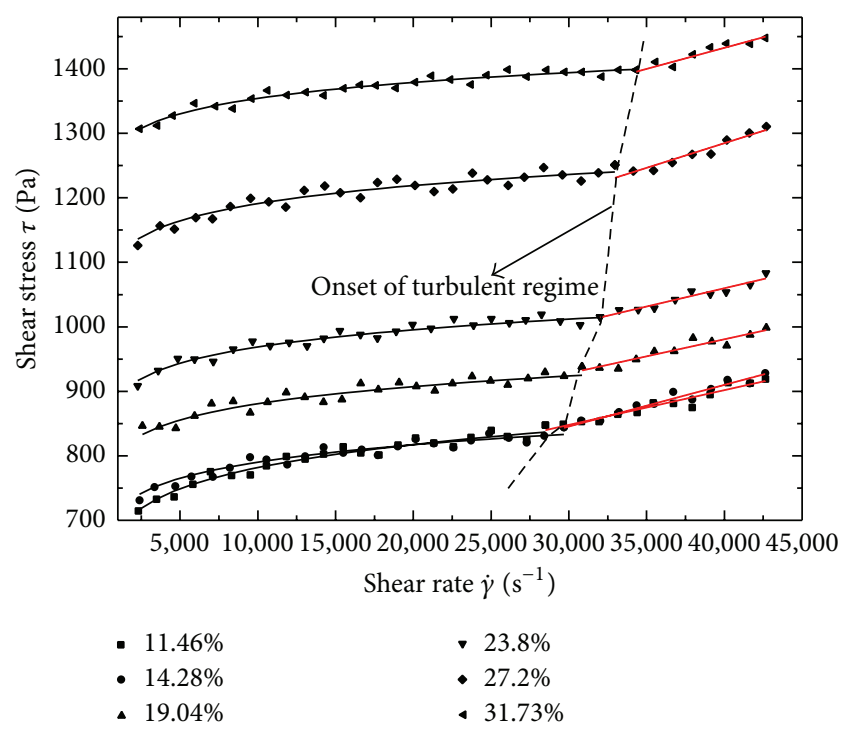

FIGURE 4: Shear stress versus shear rate of unbleached kraft pulp and several mass concentrations.

TABLE 4: Herschel-Bulkley constants for unbleached kraft pulp suspensions as a function of the fiber mass concentration.

\begin{tabular}{lccc}
\hline Mass concentration (\%) & $\tau_{y}$ & $k$ & $n$ \\
\hline 11.46 & 371 & 136 & 012 \\
14.28 & 416 & 149 & 0.1 \\
19.04 & 466 & 181 & 0.09 \\
23.8 & 529 & 201 & 0.085 \\
27.2 & 706 & 230 & 0.081 \\
31.73 & 853 & 263 & 0.07 \\
\hline
\end{tabular}

where $P$ is power (W), $\rho$ is pulp density $\left(\mathrm{kg} / \mathrm{m}^{3}\right), N$ is rotational speed $(\mathrm{r} / \mathrm{min})$, and $d$ is impeller diameter $(\mathrm{mm})$.

Figures 5 and 6 show a comparison of the power numbers of the experimental and CFD simulation results. In order to improve the ease of analysis, logarithmic coordinates were used for both the horizontal axis (rotational speed) and vertical axis (power number). The CFD results are 


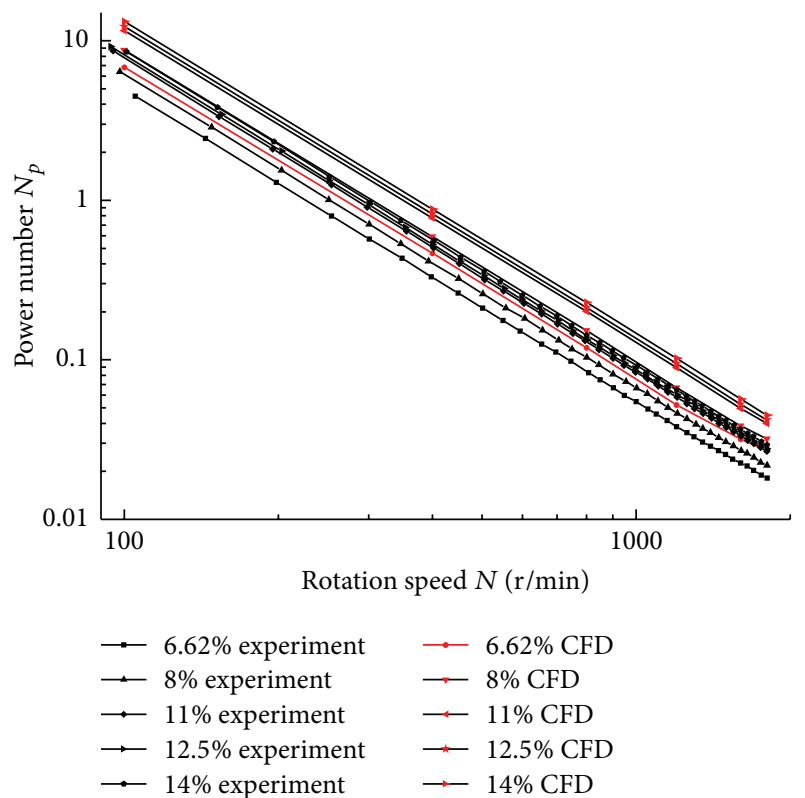

FIGURE 5: Comparison of CFD and experimental results for waste tissue pulp.

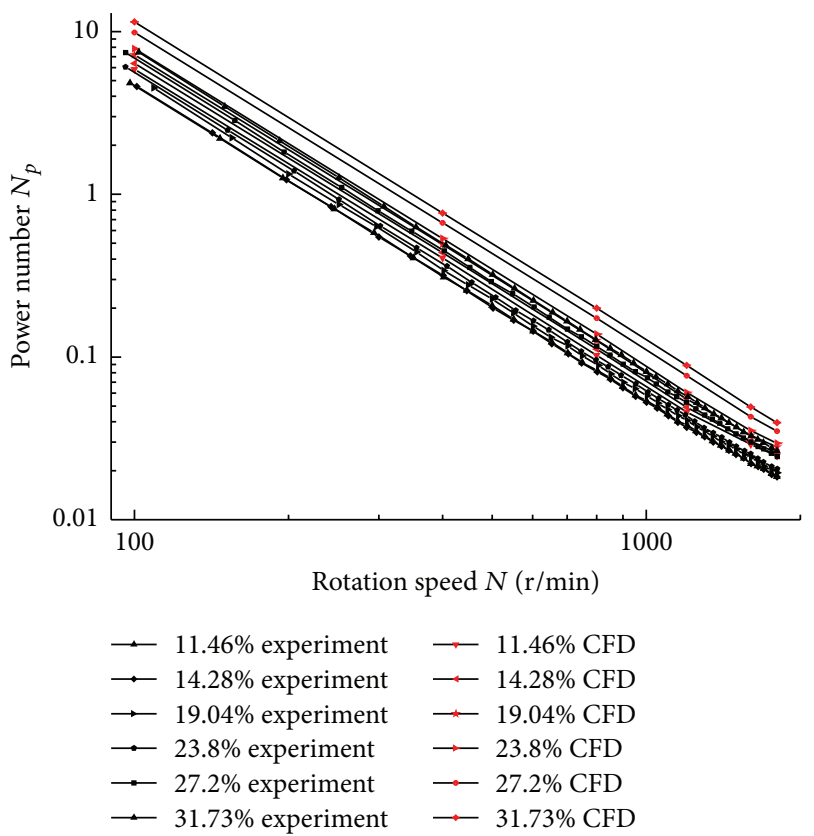

FIgURE 6: Comparison of CFD and experimental results for unbleached kraft pulp.

slightly higher than experimental values in Figures 5 and 6. The power numbers increase with increasing pulp mass concentration and decrease with impeller rotational speed. Generally, the simulated values are very similar for both waste tissue pulp and unbleached kraft pulp and are in agreement with experimental results.

4.2.1. Velocity Profiles. Figure 7 shows the velocity streamlines created by the impeller in the $11 \%$ waste tissue pulp at rotational speeds of $N=800 \mathrm{rpm}$ and $N=1800 \mathrm{rpm}$. As the rotational speed increases, the velocity magnitude increases. Because the direction of impeller rotation is positive in Figure $7(a)$, the pulp fiber suspension inflow is from the impeller inlet. The outflow portion is in the axial direction, with another portion in the radial direction. This is due to the rotational energy and the shape of the blades, which thus take on velocity energy. With centrifugal force increasing, the outflow direction changes to radial direction, as shown in Figure 7(b). In Figure 7(a), one vortex is at the impeller inlet, and another vortex is located on the right side of the impeller, indicated by black solid-border boxes. In Figure 7(b), one vortex is on the right side of impeller and another vortex is at the impeller outlet.

Figure 8 shows the velocity streamlines created by the impeller in $11.46 \%$ unbleached kraft pulp at rotational speeds of $N=800 \mathrm{rpm}$ and $N=1800 \mathrm{rpm}$. In Figure 8(a), there is only one vortex at the impeller inlet. In Figure 8(b), there are two obvious vortexes, one on the right side of the impeller and another at the impeller outlet.

Figure 9 shows the velocity streamlines created by the impeller at a speed of $N=1200 \mathrm{rpm}$. Figures 9(a), 9(b), and $9(\mathrm{c})$ show the streamlines for $6.62 \%, 11 \%$, and $14 \%$ mass concentrations of waste tissue pulp, and Figures 9(d), 9(e), and $9(f)$ show the streamlines for $11.46 \%, 19.04 \%$, and $31.73 \%$ mass concentrations of unbleached kraft pulp. There is only one vortex on the right side of the impeller. As the mass concentration increases, the streamlines clearly change, as shown in the solid-border boxes, and the apparent yield stress increases for both waste tissue pulp and unbleached kraft pulp, as shown in Tables 3 and 4. In the regions indicated by the dashed-border boxes, the streamline plots gradually become smoother as the mass concentration increases.

\section{Conclusions}

The objective of this paper was to study the rheology of medium-high-consistency pulp and determine accurate parameters for the physical Herschel-Bulkley model. To validate this model, the CFD results were compared to the experimental data. The simulation values were very similar to the experimental results. The following conclusions were obtained based on the results in this study:

(1) The shear rate and shear stress for different consistencies of both waste tissue pulp and unbleached kraft pulp were obtained experimentally. The shear stress increased with increasing shear rate and pulp consistency. The Herschel-Bulkley model was used to calculate the apparent yield stress, consistency index, and power law index values up to the onset of the turbulent regime by means of regression analysis of the experimental data. When the shear stress was in the turbulent regime, the shear stress increased linearly.

(2) Based on the Herschel-Bulkley model constants from the experimental data, pulp suspension flows were simulated for several mass concentrations of pulp. The power numbers were in good agreement with experimental results. 


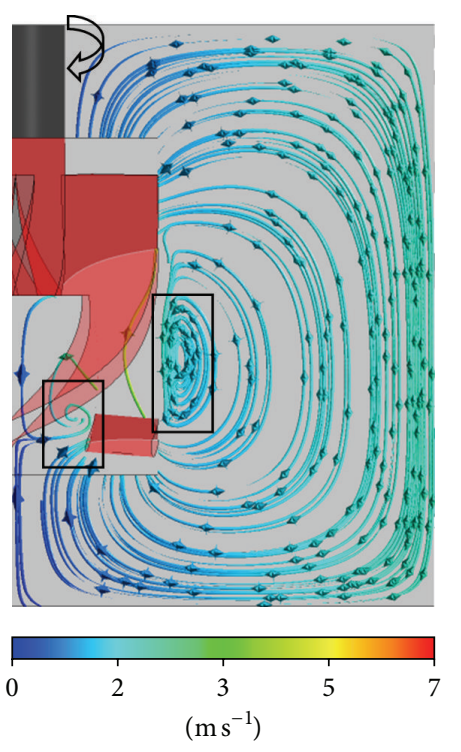

(a)

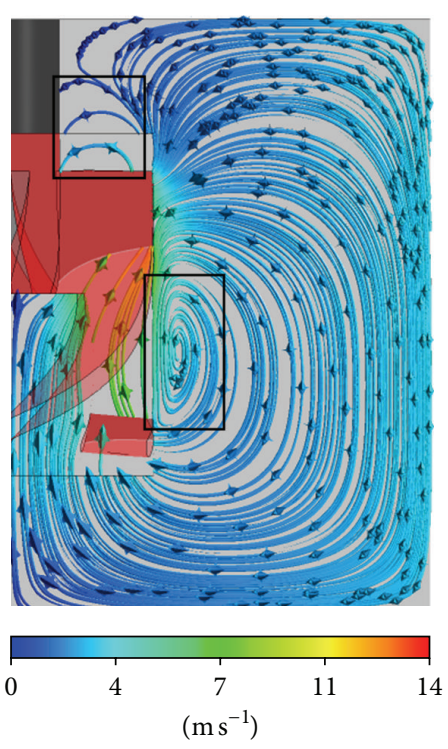

(b)

FIGURE 7: Velocity streamlines in 11\% waste tissue pulp: (a) $N=800 \mathrm{rpm}$ and (b) $N=1800 \mathrm{rpm}$.

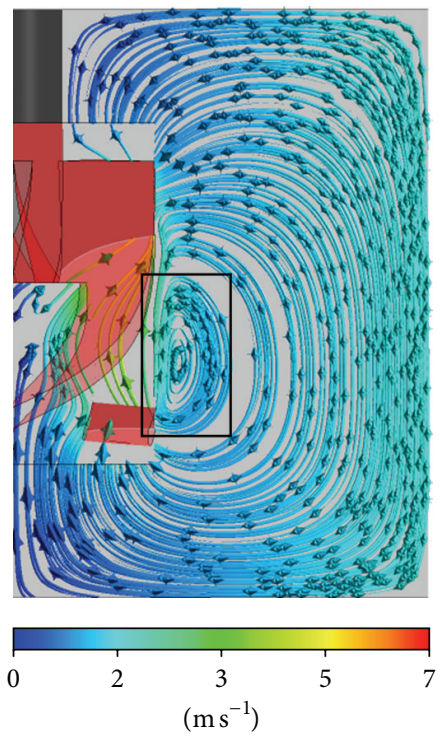

(a)

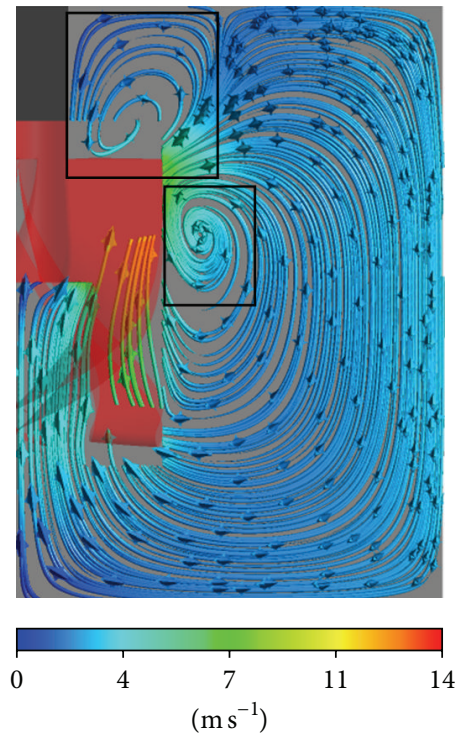

(b)

FIGURE 8: Velocity streamlines in $11.46 \%$ unbleached kraft pulp: (a) $N=800 \mathrm{rpm}$ and (b) $N=1800 \mathrm{rpm}$.

(3) The number and location of vortexes and streamlines were analyzed for different mass concentrations and speeds.

\section{Nomenclature}

$d$ : Impeller diameter, $\mathrm{mm}$

$h$ : Impeller height, $\mathrm{mm}$

$D$ : Inside diameter of vessel, $\mathrm{mm}$

$D_{1}$ : Outside diameter of vessel, $\mathrm{mm}$

$H$ : Vessel height, $\mathrm{mm}$

$c$ : Clearance from wall to bottom, $\mathrm{mm}$

P: Power, $\mathrm{W}$
$K_{s}$ : Constant value determined experimentally

$N$ : Impeller rotational speed, $\mathrm{rpm}$

$c_{w}$ : Impeller clearance from the vessel wall, $\mathrm{mm}$

$\rho:$ Pulp density, $\mathrm{kg} / \mathrm{m}^{3}$.

Greek Symbols

$\tau$ : Shear stress, $\mathrm{Pa}$

$\omega$ : Rotation angular velocity, $\mathrm{rad} / \mathrm{s}$

$t$ : Time, $\mathrm{s}$

$\vec{u}$ : Pulp flow velocity, $\mathrm{m} / \mathrm{s}$

$p$ : Static pressure, $\mathrm{Pa}$

$\overline{\bar{\tau}}$ : Viscous stress, $\mathrm{Pa}$ 


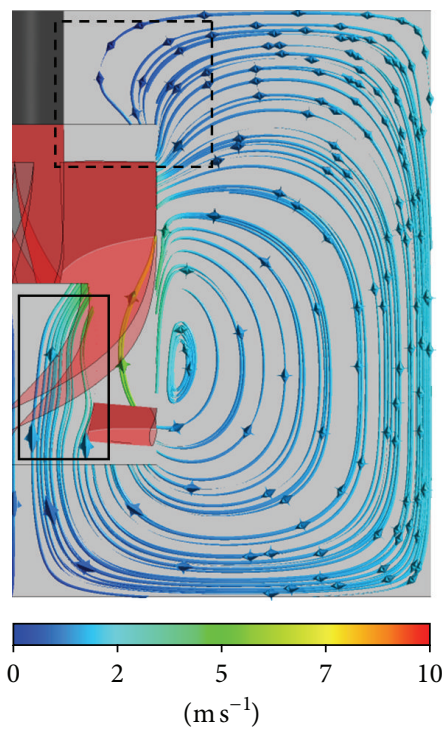

(a)
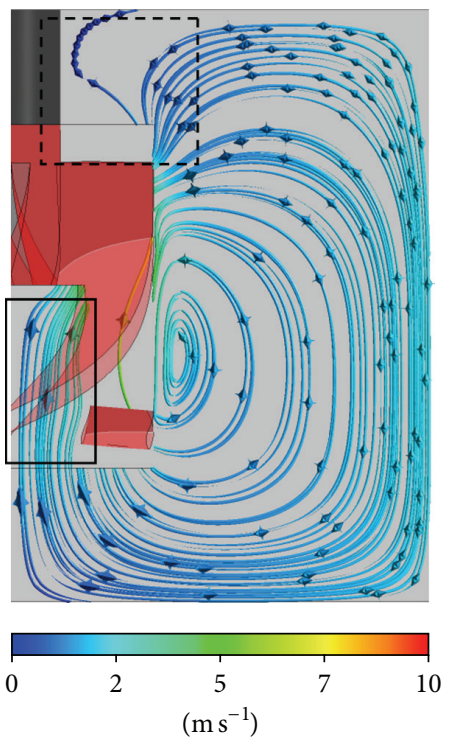

(d)

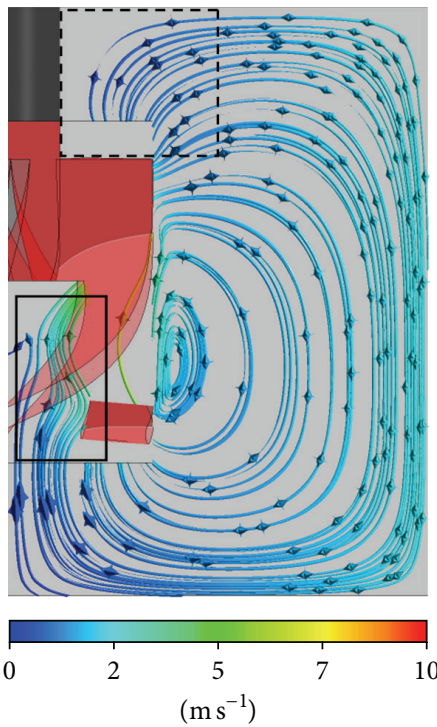

(b)

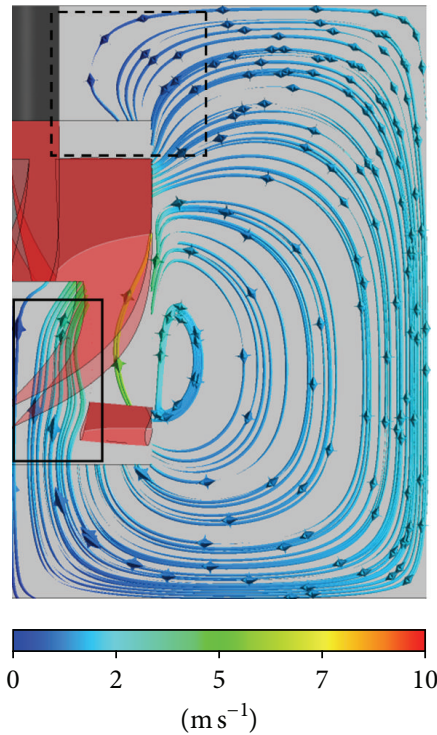

(e)

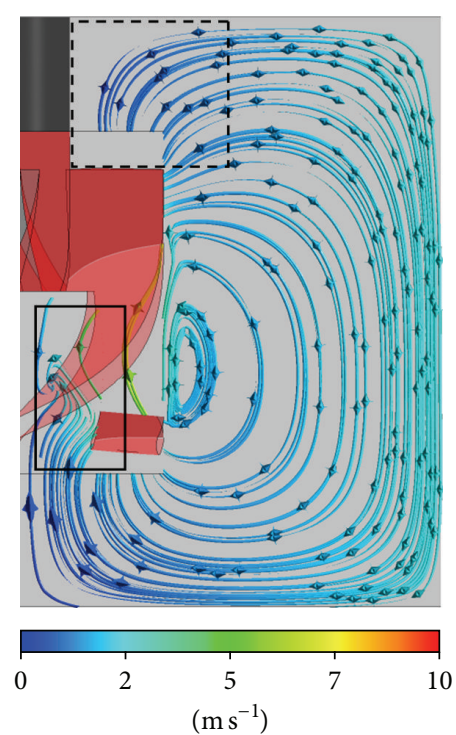

(c)

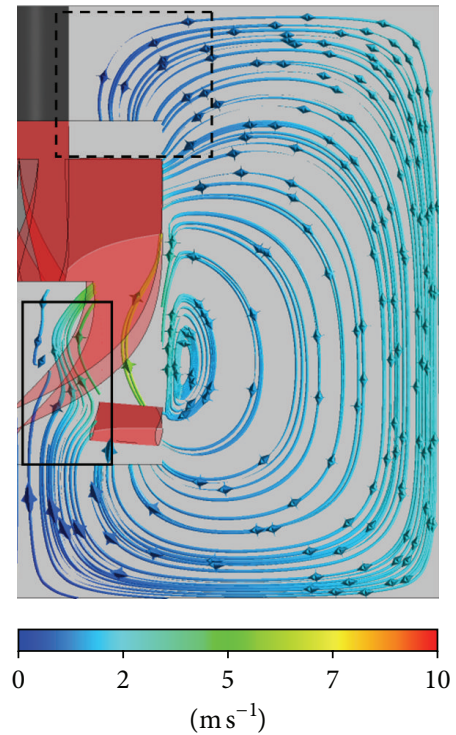

(f)

Figure 9: Velocity streamlines at $N=1200 \mathrm{rpm}$ (waste tissue pulp: (a) 6.62\%, (b) 11\%, and (c) 14\%. Unbleached kraft pulp: (d) $11.46 \%$, (e) $19.04 \%$, and (f) $31.73 \%$ ).

$\vec{F}$ : Body force, $\mathrm{N}$

$\mu_{0}$ : Yield viscosity, Pa.s

$\tau_{y}:$ Yield stress, $\mathrm{Pa}$

$k$ : Coefficient index of consistency

$\dot{\gamma}$ : Average shear rate, $\mathrm{s}^{-1}$

$n$ : Power law index.

\section{Subscripts}
s: Constant
$w$ : Vessel wall
$y$ : Yield.

\section{Competing Interests}

The authors declare that they have no competing interests.

\section{Acknowledgments}

The support of the National Natural Science Foundation of China (Grant no. 51379179) is gratefully acknowledged. The help from our research group is greatly appreciated.

\section{References}

[1] C. W. Macosko, Rheology: Principles, Measurements and Applications, Wiley-VCH, New York, NY, USA, 1994.

[2] C. P. J. Bennington, R. J. Kerekes, and J. R. Grace, "Motion of pulp fibre suspensions in rotary devices," Canadian Journal of Chemical Engineering, vol. 69, no. 1, pp. 251-258, 1991.

[3] C. P. J. Bennington and R. J. Kerekes, "Power requirements for pulp suspension fluidization," Tappi Journal, vol. 79, no. 2, pp. 253-258, 1996. 
[4] J. Hietaniemi and J. Gullichsen, "Flow properties of mediumconsistency fibre suspensions," Journal of Pulp and Paper Science, vol. 22, no. 12, pp. 469-474, 1996.

[5] G. Hemstrom, K. Moller, and B. Norman, "Boundary layer studies in pulp suspension flow," Tappi, vol. 59, no. 7, pp. 115118, 1976.

[6] G. Hemstrom, K. Moller, and B. Norman, "Boundary layer studies in plup suspension flow," Tappi, vol. 8, no. 59, pp. 151$155,1976$.

[7] G. G. Duffy and A. L. Titchener, "Disruptive shear stress of pulp networks," Svensk Papperstidning, no. 13, pp. 474-479, 1975.

[8] K.-F. Chen and S.-M. Chen, "Fluidization properties of highconsistency fiber suspensions," Experimental Thermal and Fluid Science, vol. 14, no. 2, pp. 149-159, 1997.

[9] M. Bhole, C. Ford, and C. P. J. Bennington, "Characterization of axial flow impellers in pulp fibre suspensions," Chemical Engineering Research and Design, vol. 87, no. 4, pp. 648-653, 2009.

[10] P. Prajapati and F. Ein-Mozaffari, "CFD investigation of the mixing of yield-pseudoplastic fluids with anchor impellers," Chemical Engineering and Technology, vol. 32, no. 8, pp. 12111218, 2009.

[11] B. Wu, "CFD investigation of turbulence models for mechanical agitation of non-Newtonian fluids in anaerobic digesters," Water Research, vol. 45, no. 5, pp. 2082-2094, 2011.

[12] B. Derakhshandeh, Rheology of Low to Medium Consistency Pulp Fibre Suspensions, University of British Columbia, 2011.

[13] H. Tabuteau, P. Coussot, and J. C. Baudez, "A new approach to the thixotropic behaviour of sewage sludge," Journal of Residuals Science and Technology, vol. 3, no. 4, pp. 233-240, 2006.

[14] J. C. Baudez, R. K. Gupta, N. Eshtiaghi et al., "Digested sludge rheology: similarities with soft glassy materials," in Proceedings of the 38th Australasian Chemical Engineering Conference (CHEMECA '11), pp. 1-8, 2011.

[15] C. Cotas, D. Asendrych, and G. Rasterio M, "Numerical simulation of turbulent pulp flow: influence of the non-Newtonian properties of the pulp and of the damping function," in Proceedings of the 8th International Conference for Conveying and Handling of Particulate Solids, Tel Aviv, Israel, May 2015.

[16] I. Masalova, A. Y. Malkin, E. Kharatiyan, and R. Haldenwang, "Scaling in pipeline flow of Kaolin suspensions," Journal of NonNewtonian Fluid Mechanics, vol. 136, no. 1, pp. 76-78, 2006.

[17] Z. Li, J. Li, J. Xu, L. H. Mo, Y. C. Feng, and K. F. Chen, "The fluidization properties of bagasse pulp suspensions in a rotary device," BioResources, vol. 11, no. 1, 2015.

[18] A. B. Metzner and R. E. Otto, "Agitation of non-Newtonian fluids," AIChE Journal, vol. 3, no. 1, pp. 3-10, 1957.

[19] P. Ayazi Shamlou and M. F. Edwards, "Power consumption of helical ribbon mixers in viscous Newtonian and nonNewtonian fluids," Chemical Engineering Science, vol. 40, no. 9, pp. 1773-1781, 1985.

[20] S. M. Shekhar and S. Jayanti, "Mixing of pseudoplastic fluids using helical ribbon impellers," AIChE Journal, vol. 49, no. 11, pp. 2768-2772, 2003.

[21] L. W. Adams and M. Barigou, "CFD analysis of caverns and pseudo-caverns developed during mixing of non-Newtonian fluids," Chemical Engineering Research and Design, vol. 85, no. 5, pp. 598-604, 2007.

[22] P. E. Arratia, J. Kukura, J. Lacombe, and F. J. Muzzio, "Mixing of shear-thinning fluids with yield stress in stirred tanks," AIChE Journal, vol. 52, no. 7, pp. 2310-2322, 2006.
[23] W. Kelly and B. Gigas, "Using CFD to predict the behavior of power law fluids near axial-flow impellers operating in the transitional flow regime," Chemical Engineering Science, vol. 58, no. 10, pp. 2141-2152, 2003. 


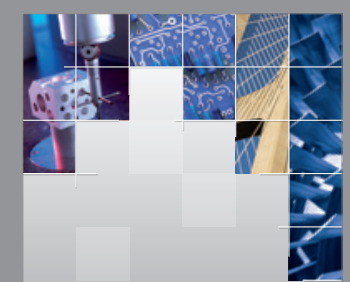

\section{Enfincering}
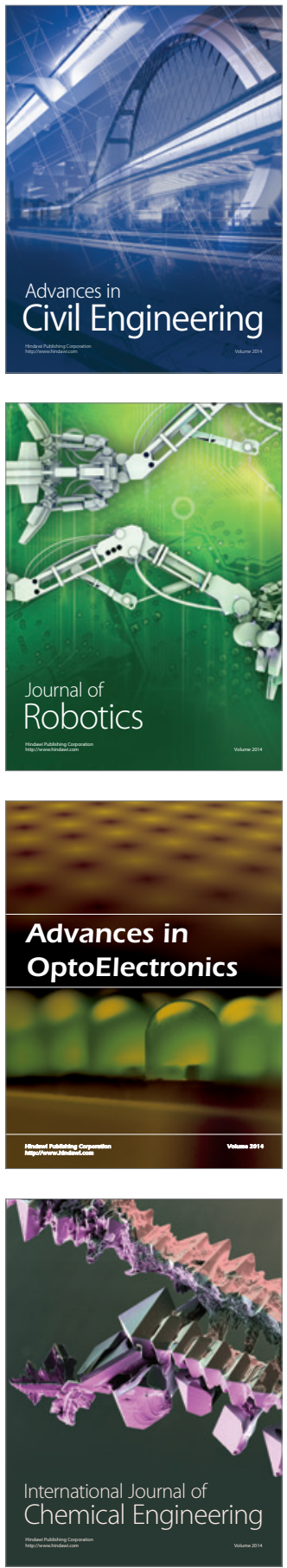

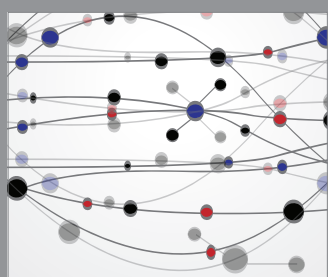

The Scientific World Journal

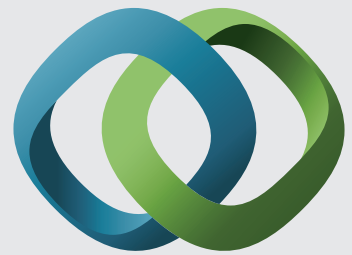

\section{Hindawi}

Submit your manuscripts at

http://www.hindawi.com
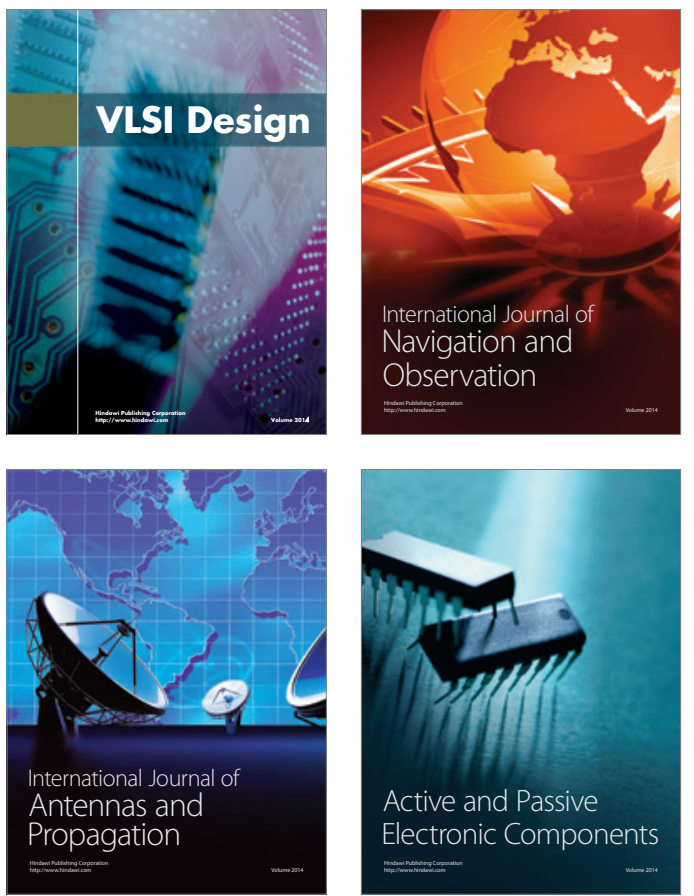
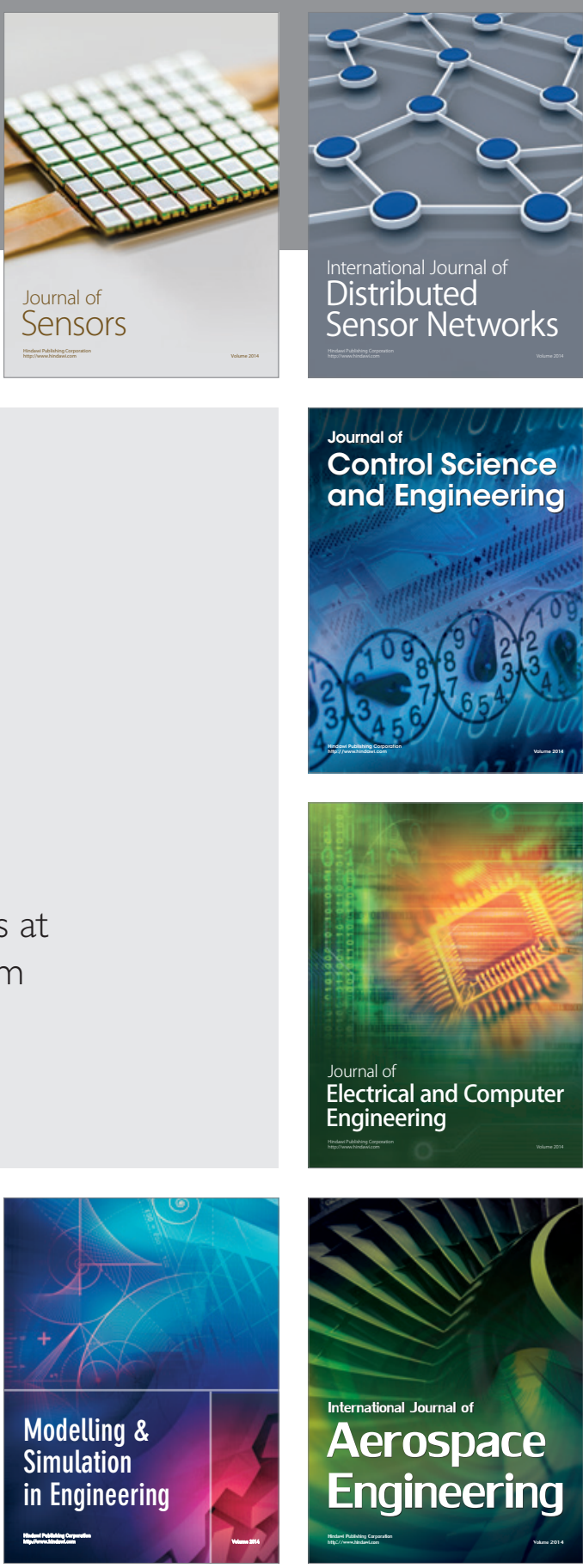

International Journal of

Distributed

Sensor Networks

Journal of

Control Science

and Engineering
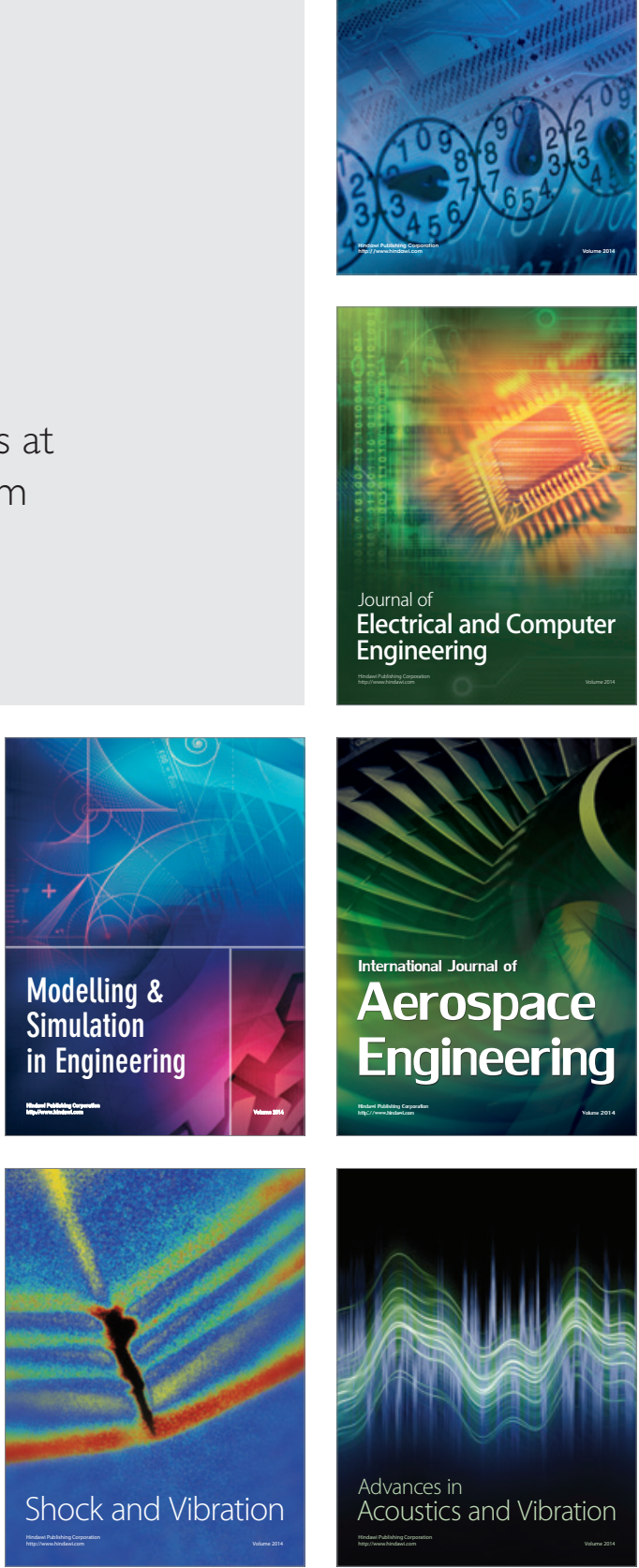